\title{
Depressive symptoms among immigrants and ethnic minorities: a population based study in 23 European countries
}

\begin{abstract}
Purpose

European studies about ethnic inequalities in depressive symptoms are scarce, show inconclusive results and are complicated by the discussion of what constitute (im)migrant and ethnic minority groups. Moreover, comparisons across countries are hampered by a lack of comparable measures of depressive symptoms. This study aims to assess the prevalence and determinants of depressive symptoms among immigrants, ethnic minorities and natives in 23 European countries.

Methods

Multilevel analyses are performed using data from the third wave of the European Social Survey (ESS3). This dataset comprises information about 36970 respondents, aged 21 years or older, of whom $13,3 \%$ immigrants and 6,2 \% ethnic minorities. Depressive symptoms were assessed with an eightitem version of the Center for Epidemiologic Studies-Depression scale. Main determinants are immigrant status, socio-economic conditions and the experience of ethnic discrimination in the host country.

Results

The results show that immigrants and ethnic minorities do experience more depressive symtoms than natives in an essential part of the countries. Moreover, socio-economic conditions and the experience of ethnic discrimination are important risk factors. Immigrant status seems irrelevant, once the other risk factors are accounted for. Finally, immigrant and ethnic minority groups do not consist of the same individuals and therefore have different prevalence rates of depressive symptoms.

Conclusions

The prevalence rates of depressive symptoms are higher for immigrant and ethnic minority groups in a substantial part of the European countries. A clear definition is indispensable for developing policies that address the right targeted population.
\end{abstract}

\section{Key words}

Depressive symptoms; Immigrants; Ethnic minorities; Europe; Ethnic discrimination

\section{Introduction}

The composition of today's European population has been characterized by 3 immigration waves in the $20^{\text {th }}$ century: around the time of the first and the second world war, and during the last decennium [1]. Approximately 56 million immigrants have now settled in Europe, and the numbers are still likely to increase [2]. While the economic consequences of migration have been frequently studied, the (mental) health consequences for immigrants have not received much attention yet.

In the United States, there exists a long tradition of research on the mental health consequences of migration [3]. Since the early 1980's epidemiological research [e.g. 4;5;6;7] challenges, the long standing tenets in psychiatry and psychology that first generation immigrants are necessarily disadvantaged [8]. Evidence is found of an (im)migrant paradox, in regard to mental health: immigrants to the USA have lower risk for mood and anxiety disorders compared with the US-born population of the same national origin $[3-5 ; 9 ; 10]$ and the native population [e.g. 11]. While some authors argue that this paradox can be explained by the healthy migrant effect - where the persons 
who migrate are the [12]-, others suggest that environmental factors in the host country, such as socio-economic conditions and the experience of ethnic discrimination are responsible [3;5;13-15].

Compared to the United States, epidemiological studies on the mental health status of immigrants in Europe are still very rare and patchy [1;16]. Immigrants are often excluded from epidemiological studies, due to methodological difficulties such as language problems and a lack of cross-culturally validated instruments $[1 ; 17]$. Most European studies are carried out in the United Kingdom [18] and focused mainly on psychotic disorders [13;19](for an overview, see Cantor-Graee \& Selten [20]). Somewhat surprisingly, very few have concentrated on depression [8], despite its more widespread manifestation [21]. Research on common mental disorders among immigrants is mostly clinical [16], uses small sample sizes and/or non-random sampling methods and yields contradictory and inconclusive results [22]. One of the reasons is the vagueness about the definition of an (im)migrant and an ethnic minority group [23]. Most authors use country of birth or self-assessment to define the groups under study and use the terms interchangeably.

A recent meta-analyse by Swinnen \& Selten [24] concluded that no evidence could be found for an elevated risk of mood disorders among immigrants and ethnic minorities. However, there were no sufficient studies to conduct an additional meta-analysis for depression. Since the overview of Carta et al. [16] only a few more population-based studies on psychological distress among immigrants have been performed, such as in Belgium [8;25], Germany [26;27], the Netherlands [28], Norway [29;30] and Sweden [31-34] with some addressing depression [8;25-28;34]. Several of these report higher levels of depression among immigrants [8;25;27;28;34], while others did not find any significant differences [26].

Between-country variation in the mental health outcomes of immigrants and ethnic minorities is expected as a result of substantial country differences in e.g. economic conditions, socio-political context and migration histories. Yet, cross national comparisons in Europe are hampered by a lack of comparable data. Until today, the report of the European Commission [35], based on the European Study of the Epidemiology of Mental Disorders (ESEMeD) findings, is the only European cross national comparison of psychological distress among immigrants. This study was carried out in six European countries and concluded that those not born in the country of residence had higher risks of psychological distress, except for Belgium. However, with respect to the research of depression among immigrants this study has three important limitations. Firstly, immigrants cannot be seen as a homogenous group [16], but the study does not consider the country or region of origin of the immigrants. Furthermore, second generations of immigrants are categorized as 'born in the country', and as such masking possible substantial differences with the native population. Thirdly, the ESEMeD project consists of a convenience sample of 4 Western-European countries (Belgium, Germany, France and the Netherlands) and 2 Southern-European countries (Spain and Italy) and does not cover the European population as a whole.

The aim of this article is to assess the prevalence and determinants of depressive symptoms among immigrants, ethnic minorities and natives, using highly comparable data from 23 European countries and to fill the gap of knowledge on this subject. Firstly, we assess whether immigrant and ethnic minority groups report more depressive symptoms than natives. Secondly, we examine whether certain much-discussed risk factors for depression can account for possible disparities between these groups. Studies examined the impact of the immigrant status, to reveal differences between first en second generations of immigrants. Acculturation, migration stress and the healthy migrant effect are put forward as explanations of these disparities. Acculturation refers to the adaption of immigrants to a new cultural context [36]. In the past, it was assumed that acculturation inevitably involves social and psychological problems [36], and that it would dissipate most of the immigrants' disadvantages in the course of time [3]. Nowadays, studies report mixed results in regard to acculturation and mental health [37]. The migration stress theory underlines the psychosocial effects of the migration 
process itself [22;38;39]. As the migration process is a period of increased stress, it would appear, according to the stress diathesis model, that emotional distress and psychiatric disorders may result from migration, leading to higher levels of depressive symptoms among first generation immigrants. On the other hand, we would find first generation immigrants to be advantaged compared to second generation immigrants, if a healthy migrant effect is occurring. This effect is explained by selective migration of healthy individuals [6].

Furthermore we test the hypothesis that elevated levels of depressive symptoms might result from precarious socio-economic conditions and the experience of ethnic discrimination in the country of residence. The impact of socio-economic conditions on depressive symptoms has been frequently demonstrated both among the general population [40;41] and immigrant and ethnic minority groups $[8 ; 25 ; 34 ; 38]$. In this study three different measures of socio-economic conditions are assessed: economic strain, labour market position and years of education. We include several measures, since evidence has shown that the association with health follows both a common and independent path. Also, some indicators might be more salient for certain subgroups [42]. And, more recently, an increasing amount of studies assess the impact of ethnic discrimination on (mental) health [43-47]. This can be an important additional risk factor, since ethnic discrimination is still widespread in Europe, even ten years after the adoption of the Racial Equality Directive (2000/43/EC), the most important piece of EU legislation combating ethnic discrimination. This is demonstrated by the results of the special Eurobarometer on discrimination. Close to one respondent in five considers ethnic discrimination to be very widespread in his or her country $(19 \%)$ and a further $45 \%$ believe it is fairly widespread. Only $2 \%$ of the interviewees believe it does not exist [48]. In this study we investigate if ethnic discrimination has an independent effect on depressive symptoms after controlling for other important risk factors such as socio-economic conditions.

Finally, by comparing the results for immigrant and ethnic minority groups, we highlight the importance of a clear definition of the population under study. Immigrants are usually defined by their country of birth and their parental country of birth, since this information is written down in censuses and death certificates [49]. Ethnicity has been operationalised in different ways, including predefined categories and self definition. Because of the shortcomings of predefined categories, self definition is gaining favor [50]. Specifically, the former do not grasp a 'sense of belonging' and 'changeability', the core aspects of ethnicity [51]. In the present study, we follow this trend and use self definition to identify ethnic minorities. Country of birth of the respondents and their parents are used for the definition of immigrants. We expect to find different results depending on the definition used, since immigrant status is a crude but objective indicator, while ethnicity is a matter of selfperception with fluid and imprecise boundaries [52]. Also, it is still not known how long before a group of immigrants will begin to constitute a socially or culturally distinct or ethnic group [23].

\section{Methods}

\section{Sample}

Our analyses are based on the third round of the European Social Survey (ESS-3, 2006-2007). The ESS is a biennial survey designed to chart and explain Europe's changing institutions and attitudes, beliefs and behavior patterns. In the third round a module on personal and social well-being has been introduced. Respondents were selected using a strict probability sample of the resident national population aged 15 or older living in a private household. Data was collected via face-to-face interviews of around an hour in duration. Translations for the questionnaires are provided for all first languages spoken by five percent or more of the population [53].

Analyses are performed on 23 of the 25 countries: Western Europe (Belgium, Germany, France, Netherlands, Austria and Switzerland), Northern Europe (Denmark, Estonia, Finland, Ireland, Norway, 
Sweden and United Kingdom), Southern Europe (Cyprus, Portugal, Slovenia and Spain) and Eastern Europe (Bulgaria, Hungary, Poland, Russia, Slovakia and Ukraine)([54], grouping aimed at discussing results). Latvia and Romania are excluded, because of missing design weights. We restricted our results to the European population, aged 21 years or older ( $\mathrm{N}=36970) .6,2 \%$ of the respondents defined themselves as belonging to an ethnic minority group and $13,3 \%$ is categorized as immigrant. High response rates are resulting from many efforts made by all countries and vary from $46 \%$ in France to $73.2 \%$ in Slovakia [55].

\section{Depressive symptoms}

Depressive symptoms are assessed with the 8-item version of the Center for Epidemiologic Studies Depression Scale (CES-D) [56]. In her original version, the CES-D consists of 20 self-report items to identify populations at risk of developing depression [57]. The CES-D 8 reports the frequency and severity of certain feelings and behaviors in the past week. Respondents are asked how often they felt depressed, felt that everything was an effort, slept restlessly, were happy, felt lonely, enjoyed life, felt sad and could not get going. Answers range from none or almost none of the time (0) to all or almost all of the time (3). The enumerated scores on the items result in a scale ranging from 0 to 24. We do not use cut-offs but consider depression as a continuous phenomenon, with higher scores marking a higher frequency and severity of depressive complaints. When four or fewer items are missing, tolerated item non-response is corrected by mean substitution, as in Van de Velde et al. [57]. This results in an overall response rate for depression of $99.5 \%$. The overall population mean for depression is $6.01(S D=4.20)$. Reliability of the CES-D 8 in our total sample was accurate as indicated by a chronbach's alpha of at least 0.83 for immigrants, ethnic minorities and natives. There is some between-country variation. For immigrants the lowest chronbach's alpha is found in Portugal $(0.73)$ and the highest in the Russian Federation (0.87), while for ethnic minorities this is the case in Slovenia (0.73) and Norway (0.90) respectively. We assume cultural validity based on studies on the CES-D 20 [e.g. 58;59;60;61], which showed measurement equivalence in different immigrant and ethnic groups. However research on the cross-cultural validity of the CES-D 8 is lacking, except for one study showing validity across European countries and gender [57].

\section{Risk and protective factors}

Respondents were categorized both according to their ethnic minority and immigrant status. Belonging to an ethnic minority ( $0=$ no; $1=y e s)$ is based on the following self report item: "Do you belong to a minority ethnic group in (country)?". When the respondents or one of their parents are born in another than the present country of residence, they are considered an immigrant $(0=n o$; $1=y e s)$. Immigrant status is assessed by means of the country of birth of the respondents and their parents. The respondent is considered i) a 'native', when born and also both parents born in the present country, ii) 'first generation', when foreign-born, iii) 'second generation', when born in the country, but both parents are foreign-born and iv) 'second generation, one parent', when born in the present country, but one of the parents is not. At last, native expats (respondents who are foreignborn, but whose both parents are natives $(\mathrm{N}=346)$ are excluded from the first generation and are considered as natives. The majority of this group moved to the present country 11 to 20 years $(14,0$ $\%)$ or more than 20 years $(79,8 \%)$ ago. Because the two native groups (i.e. 'non-immigrants' and 'non-ethnic minorities'), used as a reference category in table 3 , are not mutually exclusive, the native group in table 1 and 2 is depicted as individuals who are no immigrants, nor members of an ethnic minority.

Since the composition of immigrants and ethnic minorities differs strongly between countries [16] the region of origin is assessed in 6 categories: 'native', four categories representing the large macro 
geographical regions within Europe, as composed by the United Nations [54]: 'Western-Europe', 'Northern-Europe', 'Southern-Europe', 'Eastern-Europe' and a rest group from outside Europe. For first generation immigrants, the country of birth of the respondent is used and for second generation immigrants with one parent born abroad, the country of origin of the migrated parent. We opt to categorize the second generation immigrants by the country of birth of the father, since only 58 of them (8.63\%) have their parents coming from a different region of origin. Additional analyses (results not shown) have confirmed that results are not affected when using the maternal country of birth.

Besides immigrant status, socio-economic conditions and ethnic discrimination are important factors that might explain the relation between ethnicity and depression $[8 ; 10 ; 12 ; 38 ; 47 ; 62 ; 63]$. Socioeconomic conditions are assessed with 3 variables: economic strain, labour market position and years of education. Economic strain indicates how difficult it was to make ends meet and gives us an idea about the financial situation of the respondent. In a study on the European Community Household Panel, it was showed that household income and current life-style deprivation accounted for $84 \%$ of the between-country variation in economic strain [64]. Economic strain is assessed by the following question: "Which of the descriptions on this card comes closest to how you feel about your household's income nowadays?". Answers are 'living comfortably on present income', 'coping on present income', 'finding it difficult on present income' and 'finding it very difficult on present income'. To describe the labour market position of the last 7 days, 5 categories: 'student', 'unemployed', 'sick/handicap', 'pension' and 'other', are compared with respondents who are employed.

To identify ethnic discrimination, another important risk factor, the answers on the questions "Would you describe yourself as being a member of a group that is discriminated against in this country?" and "On what grounds is your group discriminated against?" are combined. Ethnic discrimination ( $0=n \mathrm{n}$; $1=$ yes) is registered if the respondent answers positive on the first question and reports discrimination based on skin color, race, ethnicity or nationality on the second.

The analyses are adjusted for the following control variables, which have shown relevant for depression in the general population [41;57;65-67]. We consider gender ( $0=$ male; $1=$ female) the presence of a partner ( $0=$ no; $1=$ yes) and age (in 4 categories: $21-35 ; 36-49 ; 50-64 ; 65$ or older). Partner indicates whether the respondent is married or in a civil partnership. Respondents younger than 21 years are omitted because youth depression among immigrant and ethnic minority groups requires specific attention [see e.g. 68]. As in other studies $[69 ; 70]$ we distinguish between middleaged and elderly.

\section{Analysis Procedure}

The ANOVA-procedure in SPSS 17 is used to assess differences in the prevalence of depression between natives and immigrants and ethnic minorities respectively (table 1). Simple descriptive statistics are used for an overview of the subgroups' characteristics. To identify significant differences across those groups, $\chi^{2}$-tests and one-way ANOVA were applied. Next, the MIXED model procedure in SPSS 17 is used to establish the risk factors profiles for depressive symptoms among immigrants and ethnic minorities (table 3). This procedure (also known as multilevel) allows to account for the autocorrelation between the respondents of the same country. Both fixed effects, which should be interpreted as regression coefficients, and random slopes are calculated and reported. The random slopes model accounts for the between-country differences of the association with depression. The 2 Restricted Loglikelyhood (-2LL) gives an indication of the overall goodness of the model fit, with lower scores indicating a better model. Missing data show low rates (0.0\%-1.3\%) for all risk and 
protective factors and are deleted list wise. In order to ensure the generalizability of the sample, the design weight is used to correct for slightly different probabilities of selection [53].

\section{Results}

\section{Prevalence}

Overall, immigrants and ethnic minorities in Europe are reporting significant more depressive symptoms than natives (table 1). More depressive symptoms are found for immigrants in 16 countries, with 7 countries showing significant results. For ethnic minorities this is true for 19 and 6 countries respectively. In four European countries (France, the Netherlands, Estonia and Sweden) both immigrant and ethnic minority groups report substantial more depressive symptoms than natives. In addition, higher depressive symptoms are reported by immigrants in Switzerland, Norway and Spain, and by ethnic minorities in Belgium and Denmark.

Importantly, differences are predominantly found in Western and Northern Europe, while these are absent in Eastern Europe, mainly because of the very high levels of depressive symptoms reported by the native population. These seem to be linked with the economic prosperity of the European regions. It is indeed a consistent finding that the economic prosperity of a country is linked with population health [71]. As in Lindert et al. [72], a large correlation is found between the economic development of the host country, as expressed by the gross domestic product (GDP), and the mean depression scores for both immigrants $(-0.64)$ and ethnic minorities $(-0.87)$ as for the total population $(-0.90)$ (calculations not shown).

[insert table 1 around here]

\section{Immigrant status, socio-economic conditions and ethnic discrimination}

The profiles on the risk and protective factors show substantial differences across groups. For the European sample as a whole, both immigrants and ethnic minorities are younger, experience more economic strain and ethnic discrimination than natives. All groups have a same share of men and singles, expect for more immigrants who report to be single (38.6\%, compared to $37.3 \%$ for natives). The profiles on the labour market position are not as straightforward. While immigrants have more years of education and are more often employed than natives, this is not the case for ethnic minorities. In both immigrant and ethnic minority groups, a higher proportion of unemployed $(5.9 \%$ and $9.8 \%$ compared to $3.9 \%$ ), and a lower percentage of pensioners is found (17.6\% and $19.6 \%$ compared to $23.9 \%$ ). Between the other categories, small differences exist.

[insert table 2 around here]

In table $3 a$ and $3 b$, the results of the multi-level analyses -to examine the association with the different risk factors- are shown. Model 1 and model 2 confirm the higher depression scores for immigrants of the first and second generation and for ethnic minorities, controlling for gender, the presence of a partner and age. Moreover, first generation immigrant report more depressive symptoms, followed by second generation immigrants with both parents foreign born. The mental health status of second generation immigrants with one parent foreign born is comparable to that of the native population. These findings counter the healthy migrant hypothesis, and suggest the presence of a migration stress effect or a problem of acculturation. In line with international social and psychiatric epidemiological research the risk for depression is elevated for women and singles. Also older people seem to be at a higher risk. 
Additionally, region of origin (model 2), ethnic discrimination (model 3) and socio-economic conditions (model 4) are accounted for (see table 3a). First, it is obvious that most of the mental health differences associated with immigrant status are related to the region of origin: elevated levels of depressive symptoms are mainly found among immigrants from Southern and Eastern European countries, and among immigrants from outside Europe. In effect, taking country of origin into account, immigrants with one parent foreign born actually report lower levels of depressive symptoms that the native population.

Second, the risk of depressive symptoms is increased for immigrants from Southern and Eastern Europe and from outside Europe, even after adjusting for socio-economic conditions and the experience of ethnic discrimination. Furthermore, we find lowest levels of depressive symptoms among Western-European immigrants, followed by Northern-European, Southern-European, nonEuropean, and finally Eastern-European immigrants. This ranking is similar to the overall differences in the mean level of depressive symptoms among the population of these European regions. Interestingly, additional analyses (not reported) showed that immigrants from Northern Africa ( $\mathrm{N}=$ 199) are at the highest risk for depressive symptoms.

Third, ethnic discrimination coincides compellingly with depressive symptoms, even when socioeconomic conditions are controlled for. Up to $40 \%(0.40=0.55-0.33 / 0.55)$ of the elevated level of depressive symptoms among ethnic minorities is related to the experience of ethnic discrimination. As model 4 (table 3a) shows, the remaining difference in mental health between ethnic minorities and the rest of the population is related to problems of financial strain, labour market position and years of education. Those experiencing financial constraints, the unemployed, the sick and disabled, the retired, students and, the lower educated all report more symptoms of depression. Only for students the risk for depressive symptoms is reduced. The remaining effect of immigrant status and of belonging to an ethnic minority on the frequency and severity of depressive symptoms can be completely accounted for by the cited risk factors. The -2LL parameters show the improvement of the model fit, when adding the different determinants at each step.

[insert table $3 a$ and $3 b$ around here]

\section{Immigrant versus ethnic minority groups}

In table 2, it is illustrated that immigrant and ethnic minority groups do not completely overlap. $49.3 \%$ of the self defined members of an ethnic minority are considered a native, based on their country of birth and the parental country of birth. Also, almost none of the immigrants from Western and Northern Europe and only a small proportion from Southern Europe would define themselves as a member of an ethnic minority. In addition, ethnic minorities experience more ethnic discrimination (22.3\% compared to $9.2 \%$ for immigrants) and are more frequently found in a precarious socioeconomic situation, as indicated by higher levels of economic strain, more unemployment and fewer years of education. The fact that immigrants and ethnic minorities do not constitute of the same persons was further illustrated in table 1, which showed that the higher depressive symptoms reported by immigrants are not in every country experienced by ethnic minorities and vice versa. When comparing results of other studies, attention on the definition of immigrants and ethnic minorities will need to be drawn. 


\section{Discussion}

In Europe, little is known about inequalities in depression among immigrant and ethnic groups and research is complicated by a lack of consensus on the criteria used to describe these groups $[16 ; 23]$. In this study the prevalence rates and determinants of depression among immigrants, ethnic minorities and natives are assessed in 23 European countries, using data from the third wave of the European Social Survey. This unique dataset contains information on both immigrant status and selfascribed ethnicity. Firstly, the higher prevalence rates of depression for immigrant are confirmed by recent studies for Belgium [8;25], the Netherlands [28] and Sweden [34]. In Germany, our results are consistent with Glaesmer et al. [26] who also found no elevated risk for depression among immigrants, but are in contrast with the study of Wittig et al. [27], that showed higher depression scores for Vietnamese and Polish immigrants. The higher prevalence rates for depression among ethnic minorities in the UK is also shown by Weich et al. [19] for some subgroups (middle-aged Pakistani men, older Indian and Pakistani women), while for others (Bangladeshi women) no differences with the native population are found. In the other countries, population-based studies to replicate our findings are yet to be performed. Another important observation is the high levels of depression for all individuals in Eastern European countries. This 'European East-West health divide' was also observed for both mortality and self perceived health [71;73].

Secondly, we assessed the association of well-known risk and protective factors recognized in international social and psychiatric epidemiology. Our results are consistent with the well-established fact that both women and singles are at higher risk for depression [41;57;65-67;74]. The increased risks for individuals aged 50 years or older is also reported by Stordal et al. [70]. Next, our findings are in line with other studies showing the notable impact of socio-economic conditions on depressive symptoms, both among the general population [40;41] and immigrant and ethnic minority groups $[8 ; 25 ; 34 ; 38]$.

In addition to socio-economic conditions, ethnic discrimination has been suggested as an additional risk factor, but its link with mental health has not been studied thoroughly in Europe. Our results are in line with a British study on mental disorders, which showed the deleterious effect of ethnic discrimination [45]. Interestingly, according to a special Eurobarometer, ethnic discrimination occurred most often in Sweden (85\%), the Netherlands (83\%), France $(80 \%)$, Denmark (79\%) and Belgium (78\%) [48], all of these countries show significant more depressive symptoms for ethnic minorities. And in Sweden, the Netherlands and France also immigrants reported more depressive symptoms. Without overstating, this corroborates the call to investigate the role of ethnic discrimination in more detail.

Concerning immigrant status, our results counter the healthy migrant hypothesis and do not support a straightforward acculturation or migration stress effect, since no significant differences between the generations are found, after controlling for the region of origin. However, region of origin might partially capture the migration stress and acculturation effect, since one can expect that both the stress of the migration process and the process of acculturation might be experienced differently by immigrants who come from a culturally more distinct region. Also, we have reasons to believe that the level of depression among immigrants is a reflection the mental health status of the region of origin.

Additionally, immigrant and ethnic minority groups do not comprise the same individuals. Ethnic minority groups are experiencing more ethnic discrimination and are more often found in a precarious socio-economic situation. In other studies it was also demonstrated that identification with the host society's native population was linked to a better socio-economic situation $[75 ; 76]$, and fewer experiences of ethnic discrimination $[75 ; 77]$. Hence, these groups show different prevalence 
rates of depressive symptoms. It is shown that besides the four European countries (France, the Netherlands, Estonia and Sweden) where both immigrant and ethnic minority groups report substantial more depressive symptoms than natives, higher prevalence rates for immigrants are found in Switzerland, Norway and Spain, while for ethnic minorities this is the case in the Belgium and Denmark. We therefore recommend on the necessity to make an analytical distinction between these groups, when addressing this subject.

Some limitations are worth noting. Although Van de Velde et al. [57] provide evidence for the crosscultural validity of the CES-D 8 in 25 European countries -based on data of the ESS-3-, this has not been demonstrated yet for non-European groups and groups that do not speak one of the country's main languages. The latter were not included in their study, since translations of the ESS-3 questionnaire was restricted to all languages spoken as a first language by five percent or more of their resident population [55]. It is possible that the notions of disease and symptoms have different meanings for immigrant and ethnic minority groups $[1 ; 78]$. However, the aforementioned study and the observation that $69,6 \%$ of the immigrants in our study come from within Europe, suggests that the CES-D 8 will show cross cultural validity among all immigrant and ethnic minority groups in Europe.

Another limitation is related to the use of cross-sectional data, which does not allow causal interpretations for some associations. It is also possible, for example that a worsened mental health will lead to a greater perception of ethnic discrimination [45]. Nonetheless, two longitudinal studies show that, even after controlling for prior health, discrimination precedes the elevated distress-levels $[79 ; 80]$. Also, there is concern about the shared response biases that can occur when both the measures of stress and health status are based on self-reports. However, the available evidence [e.g. 79;81] suggests that these concerns may not be contended [82].

With respect to socio-economic conditions, selection processes cannot be ruled out completely [83]. But also here, a longitudinal study shows that worsening socio-economic conditions are associated with increasing depressive symptoms [41].

Furthermore, differences between various ethnic minority groups are expected, but information on which ethnic minority group the respondent belongs to is lacking. However, migration histories are very different throughout the European countries [16] and as such, incorporating these would make the picture too complex. Also, future research should benefit from a further distinction in the group of non-European immigrants.

In addition, this study has some drawbacks that might lead to an underestimation of the prevalence and determinants of depressive symptoms among immigrant and ethnic minority groups. First of all, the impact of stress is seriously underestimated when only one outcome of the stress process is considered (e.g. depressive symptoms) [84]. Moreover, different problems that are characteristic of comparative research, such as selective non-response, different modes of data collection, translation and conduct cannot be ruled out entirely and will lead to slightly biased estimates, when they are related to depressive symptoms or one of the independents [85]. It is very likely that the less acculturated immigrants and ethnic minorities did not take part in the study, as suggested by the lower response rates reported for certain immigrant groups in the Netherlands [86]. Also, in some countries the absence of statistical significant differences in depressive symptoms might be due to a lack of statistical power as a consequence of the small amount of immigrants and ethnic minorities taking part in the survey, leading again to an underestimation.

Migration is not likely to stop in the near future, as a result of free movement from new EU member states and a tendency to recruit immigrants to fill the gaps in the labour market that are predicted to rise in the coming decennia [2]. The higher prevalence rates observed in numerous countries thus ask for adequate policies to address the special needs of these groups. Yet, only in four of the former EU15 countries (England, Italy, Netherlands and Sweden), national policies aimed at improving immigrant health have been established [87] and in almost no European country mental health care 
is designed to meet the special needs of immigrants and ethnic minorities [88]. Also, the underrepresentation in service use [89] will need to be addressed. Our findings call for more population-based studies on depression among immigrant and ethnic minority groups in Europe, and a clear definition and description of the population under study.

\section{References}

1. Lindert J, Schouler-Ocak A, Heinz A, Priebe S (2008) Mental health, health care utilisation of migrants in Europe. European Psychiatry 23:14-20

2. Boswell (2005) Migration in Europe. In: Global Commission on International Migration ed.

3. Escobar Jl, Nervi CH, Gara MA (2000) Immigration and mental health: Mexican Americans in the United States. Harvard Review of Psychiatry 8:64-72

4. Breslau J, Aguilar-Gaxiola S, Borges G, Kendler KS, Su M, Kessler RC (2007) Risk for psychiatric disorder among immigrants and their US-born descendants - Evidence from the National Comorbidity Survey Replication. Journal of Nervous and Mental Disease 195:189-195

5. Breslau J, Borges G, Hagar Y, Tancredi D, Gilman S (2009) Immigration to the USA and risk for mood and anxiety disorders: variation by origin and age at immigration. Psychological Medicine 39:1117-1127

6. Burnam MA, Hough RL, Karno M, Escobar JI, Telles CA (1987) Acculturation and Lifetime Prevalence of Psychiatric-Disorders Among Mexican-Americans in Los-Angeles. Journal of Health and Social Behavior 28:89-102

7. Vega WA, Kolody B, Valle JR (1987) Migration and Mental-Health - An Empirical-Test of Depression Risk-Factors Among Immigrant Mexican Women. International Migration Review 21:512-530

8. Levecque K, Lodewyckx I, Bracke P (2008) Psychological distress, depression and generalised anxiety in Turkish and Moroccan immigrants in Belgium-a general population study. Social Psychiatry and Psychiatric Epidemiology 44:188-197

9. Alegria M, Canino G, Shrout PE, Woo M, Duan N, Vila D, Torres M, Chen CN, Meng XL (2008) Prevalence of mental illness in immigrant and non-immigrant U.S. Latino groups. American Journal of Psychiatry 165:359-369

10. Vega WA, Kolody B, Aguilar-Gaxiola S, Alderete E, Catalano R, Caraveo-Anduaga J (1998) Lifetime prevalence of DSM-III-R psychiatric disorders among urban and rural Mexican Americans in California. Archives of General Psychiatry 55:771-778

11. Cheng ATA, Chang JC (1999) Mental health aspects of culture and migration. Current Opinion in Psychiatry 12:217-222

12. Miranda J, Siddique J, Belin TR, Kohn-Wood LP (2005) Depression prevalence in disadvantaged young black women-African and Caribbean immigrants compared to US-born African Americans., pp. 253-258 
13. Bhugra D, Mastrogianni A (2004) Globalisation and mental disorders - Overview with relation to depression. British Journal of Psychiatry 184:10-20

14. Nazroo JY (1997) The health of Britain's ethnic minorities : findings from a national survey. Policy Studies Institute, London

15. Sole-Auro A, Crimmins EM (2008) Health of Immigrants in European Countries. International Migration Review 42:861-876

16. Carta MG, Bernal M, Hardoy MC, Haro-Abad JM, "Report on the Mental Health in Europe" working group (2005) Migration and mental health in Europe (the state of the mental health in Europe working group: appendix I).

17. Alonso J, Angermeyer MC, Bernert S, Bruffaerts R, Brugha IS, Bryson $H$, de Girolamo $G$, de Graaf R, Demyttenaere K, Gasquet I, Haro JM, Katz SJ, Kessler RC, Kovess V, Lepine JP, Ormel J, Polidori G, Russo LJ, Vilagut G, Almansa J, Arbazadeh-Bouchez $S$, Autonell J, Bernal M, Buist-Bouwman MA, Codony M, Domingo-Salvany A, Ferrer M, Joo SS, Martinez-Alonso M, Matschinger H, Mazzi F, Morgan Z, Morosini P, Palacin C, Romera B, Taub N, Vollebergh WAM (2004) Use of mental health services in Europe: results from the European Study of the Epidemiology of Mental Disorders (ESEMeD) project. Acta Psychiatrica Scandinavica 109:4754

18. Claassens D, Ascoli M, Berhe T, Priebe S (2005) Research on mental disorders and their care in immigrant populations: a review of publications from Germany, Italy and the UK., pp. 540549

19. Weich S, Nazroo J, Sproston K, McManus S, Blanchard M, Erens B, Karlsen S, King M, Lloyd K, Stansfeld S, Tyrer P (2004) Common mental disorders and ethnicity in England: the EMPIRIC Study. Psychological Medicine 34:1543-1551

20. Cantor-Graae E, Selten JP (2005) Schizophrenia and migration: A meta-analysis and review. American Journal of Psychiatry 162:12-24

21. World Health organization (2005) Mental health:facing the challenges, building solutions. Report from the WHO ministerial conference. The regional office for Europe of the World Health organization,

22. Bhugra D, Still R, Furnham A, Bochner S (2004) Migration and mental health. Acta Psychiatrica Scandinavica 109:243-258

23. Mladovsky P (2007) Migration and health in the EU. Research Note for the European Commission. DG Employment and Social Affairs,

24. Swinnen SGHA, Selten JP (2007) Mood disorders and migration - Meta-analysis. British Journal of Psychiatry 190:6-10

25. Levecque K, Lodewyckx I, Vranken J (2007) Depression and generalised anxiety in the general population in Belgium: A comparison between native and immigrant groups. Journal of Affective Disorders 97:229-239

26. Glaesmer H, Wittig U, Brahler E, Martin A, Mewes R, Rief W (2009) Are Migrants More Susceptible to Mental Disorders? An Evaluation of a Representative Sample of the German General Population. Psychiatrische Praxis 36:16-22 
27. Wittig U, Lindert J, Merbach M, Braehler E (2008) Mental health of patients from different cultures in Germany. European Psychiatry 23:28-35

28. De Wit MAS, Tuinebreijer WC, Dekker J, Beekman AJTF, Gorissen WHM, Schrier AC, Penninx BWJH, Komproe IH, Verhoeff AP (2008) Depressive and anxiety disorders in different ethnic groups A population based study among native Dutch, and Turkish, Moroccan and Surinamese migrants in Amsterdam. Social Psychiatry and Psychiatric Epidemiology 43:905912

29. Dalgard OS, Thapa SB, Hauff E, McCubbin M, Syed HR (2006) Immigration, lack of control and psychological distress: Findings from the Oslo Health Study. Scandinavian Journal of Psychology 47:551-558

30. Thapa SB, Dalgard OS, Claussen B, Sandvik L, Hauff E (2007) Psychological distress among immigrants from high- and low-income countries: Findings from the Oslo Health Study. Nordic Journal of Psychiatry 61:459-465

31. Blomstedt Y, Johansson SE, Sundquist J (2007) Mental health of immigrants from the former Soviet Bloc: a future problem for primary health care in the enlarged European Union? A cross-sectional study. Bmc Public Health 7:27

32. Syed HR, Dalgard OS, Dalen I, Claussen B, Hussain A, Selmer R, Ahlberg N (2006) Psychosocial factors and distress: a comparison between ethnic Norwegians and ethnic Pakistanis in Oslo, Norway. Bmc Public Health 6:182

33. Taloyan M, Johansson SE, Sundquist J, Kocturk TO, Johansson LM (2008) Psychological distress among Kurdish immigrants in Sweden. Scandinavian Journal of Public Health 36:190196

34. Thinghög P, Hemmingsson T, Lundberg I (2007) To what extent may the association between immigrant status and mental illness be explained by socioeconomic factors? Social Psychiatry Psychiatric epidemiology 42:990-996

35. European Commission (2004) The State of the Mental Health in Europe.

36. Berry JW (1997) Immigration, acculturation, and adaptation. Applied Psychology-An International Review-Psychologie Appliquee-Revue Internationale 46:5-34

37. Koneru VK, de Mamani AGW, Flynn PM, Betancourt H (2007) Acculturation and mental health: Current findings and recommendations for future research. Applied \& Preventive Psychology 12:76-96

38. Nazroo JY (2003) The structuring of ethnic inequalities in health: Economic position, racial discrimination, and racism. American Journal of Public Health 93:277-284

39. Smaje C (1996) The ethnic patterning of health: New directions for theory and research. Sociology of Health \& Illness 18:139-171

40. Lorant V, Deliege D, Eaton W, Robert A, Philippot P, Ansseau M (2003) Socioeconomic inequalities in depression: A meta-analysis. American Journal of Epidemiology 157:98-112 
41. Lorant V, Croux C, Weich S, Deliege D, Mackenbach J, Ansseau M (2007) Depression and socio-econornic risk factors: 7-year longitudinal population study. British Journal of Psychiatry 190:293-298

42. Robert SA, House JS (2000) Socioeconomic inequalities in health: an enduring sociological problem. In: Bird CE, Conrad P, Fremont AM eds. Handbook of medical sociology. Prentice Hall, Upper Saddle River, N.J., pp. 79-97

43. Gee GC (2002) A multilevel analysis of the relationship between institutional and individual racial discrimination and health status. American Journal of Public Health 92:615-623

44. Harris R, Tobias M, Jeffreys M, Waldegrave K, Karlsen S, Nazroo J (2006) Racism and health: The relationship between experience of racial discrimination and health in New Zealand. Social Science \& Medicine 63:1428-1441

45. Karlsen S, Nazroo JY, McKenzie K, Bhui K, Weich S (2005) Racism, psychosis and common mental disorder among ethnic minority groups in England. Psychological Medicine 35:17951803

46. Krieger N (2000) Discrimination and health. In: Berkman LF, Kawachi I eds. Social epidemiology. Oxford University Press, New York, pp. 36-75

47. Williams DR, Mohammed SA (2009) Discrimination and racial disparities in health: evidence and needed research. Journal of Behavioral Medicine 32:20-47

48. European Commission (2007) Discrimination in the European Union. European Commission, DG Employment, Social Affairs and Equal Opportunities,

49. Nazroo JY (1998) Genetic, cultural or socio-economic vulnerability? Explaining ethnic inequalities in health. Sociology of Health \& Illness 20:710-730

50. Bhopal R (2004) Glossary of terms relating to ethnicity and race: for reflection and debate. Journal of Epidemiology and Community Health 58:441-445

51. McKenzie K, Fearon P, Hutchinson G (2008) Migration, ethnicity and psychosis. In: Morgan C, McKenzie K, Feron P eds. Society and psychosis. Cambridge University Press, Cambridge, pp. 143-160

52. Senior PA, Bhopal R (1994) Ethnicity As A Variable in Epidemiologic Research. British Medical Journal 309:327-330

53. European Social survey (2007) European social survey. http://www.europeansocialsurvey.org

54. United Nations Statistics division (2010) Composition of macro geographical (continental) regions, geographical sub-regions, and selected economic and other groupings.

55. Jowell R, and the Central Coordinating Team, European Social Survey 2006/2007 (2007) Technical Report. Centre for Comparative Social Survey, City University, London

56. Radloff LS (1977) The CES-D Scale: A Self-Report Depression Scale for Research in the General. Applied Psychological Measurement 1:385-401 
57. Van de Velde S, Bracke P, Levecque K, Meuleman B (2010) Gender differences in depression in 25 European countries after eliminating measurement bias in the CES-D 8. Social Science Research 39:396-404

58. Chapela IB, de Snyder NS (2009) Psychometric characteristics of the Center for Epidemiological Studies-depression Scale (CES-D), 20-and 10-item versions, in women from a Mexican rural area. Salud Mental 32:299-307

59. Cheung CK, Bagley C (1998) Validating an American scale in Hong Kong: The Center for Epidemiological Studies Depression Scale (CES-D). Journal of Psychology 132:169-186

60. Fountoulakis K, lacovides A, Kleanthous S, Samolis S, Kaprinis SG, Sitzoglou K, St KG, Bech P (2001) Reliability, validity and psychometric properties of the Greek translation of the Center for Epidemiological Studies-Depression (CES-D) Scale. BMC Psychiatry 1:3

61. Spijker J, van der Wurff FB, Poort EC, Smits CHM, Verhoeff AP, Beekman ATF (2004) Depression in first generation labour migrants in Western Europe: the utility of the Center for Epidemiologic Studies Depression Scale (CES-D). International Journal of Geriatric Psychiatry 19:538-544

62. Lorant $\mathrm{V}$, van Oyen $\mathrm{H}$, Thomas I (2008) Contextual factors and immigrants' health status: Double jeopardy. Health \& Place 14:678-692

63. Paradies $Y$ (2006) A systematic review of empirical research on self-reported racism and health. International Journal of Epidemiology 35:888-901

64. Whelan CT, Layte R, Maitre B, Nolan B (2001) Income, deprivation, and economic strain. An analysis of the European community household panel. European Sociological Review 17:357372

65. Levecque K (2006) Generalized anxiety and depression in the general population: Risk factors according to the Belgian Health Interview Survey 2001. Depression and Anxiety 23:509-511

66. Mirowsky J, Ross CE (1986) Social Patterns of Distress. Annual Review of Sociology 12:23-45

67. World Health organization (2000) Crossnational comparisons of the prevalences and correlates of mental disorders. Bulletin of the World Health Organization 78:413-426

68. Hovey JD, King CA (1996) Acculturative stress, depression, and suicidal ideation among immigrant and second-generation Latino adolescents. Journal of the American Academy of Child and Adolescent Psychiatry 35:1183-1192

69. Mirowsky J, Ross CE (1992) Age and Depression. Journal of Health and Social Behavior 33:187-205

70. Stordal E, Kruger MB, Dahl NH, Kruger O, Mykletun A, Dahl AA (2001) Depression in relation to age and gender in the general population: the Nord-Trondelag Health Study (HUNT). Acta Psychiatrica Scandinavica 104:210-216

71. Olsen KM, Dahl SA (2007) Health differences between European countries. Social Science \& Medicine 64:1665-1678 
72. Lindert J, von Ehrenstein OS, Priebe S, Mielck A, Brahler E (2009) Depression and anxiety in labor migrants and refugees - A systematic review and meta-analysis. Social Science \& Medicine 69:246-257

73. Carlson $\mathrm{P}$ (2004) The European health divide: a matter of financial or social capital? Social Science \& Medicine 59:1985-1992

74. Bracke $P(2000)$ The three-year persistence of depressive symptoms in men and women. Social Science \& Medicine 51:51-64

75. Nesdale D (2002) Acculturation attitudes and the ethnic and host-country identification of immigrants. Journal of Applied Social Psychology 32:1488-1507

76. Van Craen M, Vancluysen K, Ackaert J (2007) Voorbij wij en zij? Vanden Broele, Brugge

77. Walters D, Phythian K, Anisef $P$ (2007) The acculturation of Canadian immigrants: Determinants of ethnic identification with the host society. Canadian Review of Sociology and Anthropology-Revue Canadienne de Sociologie et D Anthropologie 44:37-64

78. Feeney LK, Kelly BD (2008) Coping with stressors: racism and migration Larkin Feeney and Brendan D. Kelly. In: Bhugra D, Bhui K eds. Textbook of Cultural Psychiatry. Cambridge University Press, Cambridge, pp. 550-560

79. Brown TN, Williams DR, Jackson JS, Neighbors HW (2000) "Being black and feeling blue": the mental health consequences of racial discrimination. Race \& Society 2:117-131

80. Pavalko EK, Mossakowski KN, Hamilton VJ (2003) Does perceived discrimination affect health? Longitudinal relationships between work discrimination and women's physical and emotional health., pp. 18-33

81. Ruggiero KM, Taylor DM (1997) Why minority group members perceive or do not perceive the discrimination that confronts them: The role of self-esteem and perceived control. Journal of Personality and Social Psychology 72:373-389

82. Williams DR, Neighbors HW, Jackson JS (2003) Racial/ethnic discrimination and health: Findings from community studies. American Journal of Public Health 93:200-208

83. Levecque K (2008) Armoede en depressie - Een (niet) evident verband? Acco, Leuven

84. van Praag L, Bracke P, Christiaens W, Levecque K, Pattyn E (2009) Mental health in a gendered context: Gendered community effect on depression and problem drinking. Health \& Place 15:990-998

85. Van de Velde S, Bracke P, Levecque K (2009) Gender difference in depression in 23 European countries. Cross-national variation in the gender gap in depression? Annual Meeting American Sociological Association.

86. Fassaert T, De Wit MAS, Tuinebreijer WC, Verhoeff AP, Beekman ATF, Dekker J (2009) Perceived need for mental health care among non-western labour migrants. Social Psychiatry and Psychiatric Epidemiology 44:208-216

87. Mladovsky P (2009) A framework for analysing migrant health policies in Europe. Health Policy 93:55-63 
88. Watters C (2002) Migration and mental health care in Europe: report of a preliminary mapping exercise., pp. 153-172

89. Kirmayer LJ, Weinfeld M, Burgos G, du Fort GG, Lasry JC, Young A (2007) Use of health care services for psychological distress by immigrants in an urban multicultural milieu. Canadian Journal of Psychiatry-Revue Canadienne de Psychiatrie 52:295-304

\section{Tables}

Table 1: Mean depression scores of the total European population, immigrants, ethnic minorities and natives (non-immigrants, nonethnic minorities), aged 21 or older, $\chi^{2}$-test. ESS-3, 2006-2007 (weighted data)

\begin{tabular}{|c|c|c|c|c|c|c|c|c|c|c|}
\hline & \multicolumn{2}{|c|}{ Total } & \multicolumn{3}{|c|}{ Immigrants } & \multicolumn{3}{|c|}{ Ethnic minorities } & \multicolumn{2}{|c|}{ Natives } \\
\hline & $\mathrm{N}$ & Mean & $\mathrm{N}$ & Mean & & $\mathrm{N}$ & Mean & & $\mathrm{N}$ & Mean \\
\hline \multicolumn{11}{|l|}{ Western Europe } \\
\hline Austria & 1880 & 5.26 & 259 & 5.52 & & 50 & 5.64 & & 1602 & 5.20 \\
\hline Belgium & 1590 & 5.43 & 237 & 5.96 & & 32 & 7.53 & 2 & 1347 & 5.33 \\
\hline France & 1755 & 5.33 & 341 & 5.94 & 1 & 62 & 6.69 & 2 & 1398 & 5.17 \\
\hline Germany & 2550 & 6.03 & 357 & 6.23 & & 110 & 6.07 & & 2163 & 5.99 \\
\hline Netherlands & 1732 & 6.03 & 239 & 6.01 & 1 & 100 & 7.33 & 2 & 2163 & 5.99 \\
\hline Switzerland & 1615 & 4.62 & 541 & 5.00 & 1 & 104 & 5.13 & & 1055 & 4.40 \\
\hline Total & 11122 & 5.34 & 1974 & 5.69 & 1 & 458 & 6.27 & 2 & 9054 & 5.26 \\
\hline \multicolumn{11}{|l|}{ Northern Europe } \\
\hline Denmark & 1344 & 4.71 & 134 & 5.25 & & 30 & 6.70 & 2 & 1203 & 4.66 \\
\hline Estonia & 1222 & 6.91 & 494 & 7.36 & 1 & 365 & 7.33 & 2 & 689 & 6.59 \\
\hline Finland & 1710 & 4.95 & 28 & 6.11 & & 13 & 4.00 & & 1671 & 4.94 \\
\hline Ireland & 1393 & 4.67 & 185 & 4.83 & & 46 & 4.79 & & 1188 & 4.65 \\
\hline Norway & 1549 & 4.19 & 133 & 5.07 & 1 & 33 & 5.12 & & 1403 & 4.11 \\
\hline Sweden & 1721 & 4.92 & 316 & 5.58 & 1 & 41 & 7.56 & 2 & 1401 & 4.77 \\
\hline United Kingdom & 2040 & 5.58 & 274 & 5.50 & & 111 & 6.31 & & 1740 & 5.58 \\
\hline Total & 10979 & 5.11 & 1564 & 5.98 & 1 & 639 & 6.77 & 2 & 9295 & 4.96 \\
\hline \multicolumn{11}{|l|}{ Southern Europe } \\
\hline Cyprus & 873 & 5.12 & 46 & 5.12 & & 17 & 4.40 & & 816 & 5.14 \\
\hline Portugal & 1865 & 7.38 & 130 & 6.87 & & 87 & 7.72 & & 1671 & 7.39 \\
\hline Slovenia & 1180 & 5.87 & 194 & 5.74 & & 36 & 6.17 & & 967 & 5.90 \\
\hline Spain & 1613 & 5.72 & 140 & 6.63 & 1 & 60 & 6.44 & & 1437 & 5.63 \\
\hline Total & 5531 & 6.21 & 510 & 6.22 & & 200 & 6.78 & & 4891 & 6.20 \\
\hline \multicolumn{11}{|l|}{ Eastern Europe } \\
\hline Bulgaria & 1146 & 7.84 & 41 & 7.83 & & 179 & 8.48 & & 928 & 7.71 \\
\hline Hungary & 1371 & 8.42 & 78 & 8.31 & & 76 & 8.75 & & 1218 & 8.41 \\
\hline Poland & 1446 & 6.85 & 64 & 7.44 & & 14 & 8.04 & & 1372 & 6.82 \\
\hline Russian Federation & 1893 & 7.87 & 225 & 7.93 & & 373 & 7.57 & & 1373 & 7.96 \\
\hline Slovakia & 1377 & 7.44 & 88 & 6.68 & & 116 & 8.32 & & 1186 & 7.42 \\
\hline Ukraine & 1641 & 8.51 & 310 & 8.96 & & 70 & 7.68 & & 1290 & 8.48 \\
\hline Total & 8874 & 7.83 & 806 & 8.18 & & 828 & 8.00 & & 7367 & 7.80 \\
\hline Total & 36506 & 6.01 & 4854 & 6.25 & 1 & 2125 & 7.14 & 2 & 30607 & 5.93 \\
\hline
\end{tabular}

Source: European Social Survey, $3^{\mathrm{e}}$ round, own calculations

1: difference between immigrants and natives is significant $(\mathrm{p}>0.05)$

2: difference between ethnic minorities and natives is significant $(\mathrm{p}>0.05)$ 
Table 2: Characteristics of the European population by belonging to an immigrant, ethnic minority or native (non-immigrant, non-ethnic minority) group, aged 21 or older, ESS-3, 2006-2007 (weighted N, weighted $\%$, weighted mean)

\begin{tabular}{|c|c|c|c|}
\hline & $\begin{array}{r}\text { Immigrants } \\
(\mathrm{N}=4852)\end{array}$ & $\begin{array}{r}\text { Ethnic } \\
\text { minorities } \\
(\mathrm{N}=2125)\end{array}$ & $\begin{array}{r}\text { Natives } \\
(\mathrm{N}=30607)\end{array}$ \\
\hline \multicolumn{4}{|l|}{ Gender $(N(\%))$} \\
\hline Male & $2232(46.0)$ & $995(46.8)$ & $14137(46.2)$ \\
\hline \multicolumn{4}{|l|}{ Partner (N(\%)) } \\
\hline Yes & $2978(61.4)^{1}$ & $1345(63.3)$ & $19200(62.7)$ \\
\hline \multicolumn{4}{|l|}{$\operatorname{Age}(N(\%))$} \\
\hline $21-35$ years & $2894(59.6)^{1}$ & $1317(62.0)^{2}$ & $7178(23.5)$ \\
\hline $36-49$ years & & & $8485(27.7)$ \\
\hline $50-64$ years & $1197(24.7)$ & $473(22.3)$ & $8342(27.3)$ \\
\hline 65 or older & $761(15.7)$ & $334(15.7)$ & $6603(21.6)$ \\
\hline \multicolumn{4}{|l|}{ Immigrant status $(N(\%))$} \\
\hline Native & $0(0.0)$ & $1047(49.3)^{2}$ & $30607(100.0)$ \\
\hline First generation & $2554(52.7)$ & 813 (38.2) & \\
\hline Second generation, one parent & $1661(34.2)$ & $87(4.1)$ & \\
\hline Second generation & $637(13.1)$ & $178(8.4)$ & \\
\hline \multicolumn{4}{|l|}{ Region of origin $(N(\%))$} \\
\hline Native & $0(0.0)$ & $1047(49.3)^{2}$ & $30607(100.0)$ \\
\hline Western Europe & $720(14.8)$ & $17(0.8)$ & \\
\hline Northern Europe & $514(10.6)$ & $41(1.9)$ & \\
\hline Southern Europe & $685(14.1)$ & $97(4.5)$ & \\
\hline Eastern Europe & $1459(30.1)$ & $433(20.4)$ & \\
\hline Outside Europe & $1473(30.4)$ & $491(23.1)$ & \\
\hline \multicolumn{4}{|l|}{ Economic strain $(N(\%))$} \\
\hline Finding it very difficult & $402(8.3)^{1}$ & $375(17.6)^{2}$ & $2029(6.6)$ \\
\hline Finding it difficult & $1026(21.2)$ & $649(30.5)$ & $5488(17.9)$ \\
\hline Coping & $2117(43.6)$ & $834(39.3)$ & $13926(45.5)$ \\
\hline Living comfortably & $1306(26.9)$ & $267(12.6)$ & 9165 (29.9) \\
\hline \multicolumn{4}{|l|}{ Labour market position $(N(\%))$} \\
\hline Employed & $2816(58.0)^{1}$ & $1108(52.2)^{2}$ & 16905 (55.2) \\
\hline Student & $189(3.9)$ & $68(3.2)$ & $900(2.9)$ \\
\hline Unemployed & $284(5.9)$ & $206(9.7)$ & $1179(3.9)$ \\
\hline Sick/handicap & $116(2.4)$ & $55(2.6)$ & $753(2.5)$ \\
\hline Pension & $854(17.6)$ & $417(19.6)$ & $7312(23.9)$ \\
\hline Other & $594(12.2)$ & $271(12.7)$ & $3559(11.6)$ \\
\hline Years of education (Mean, SD) & $12.91(4.21)^{1}$ & $11.62(4.25)^{2}$ & $12.28(4.12)$ \\
\hline \multicolumn{4}{|l|}{ Ethnic discrimination $(N(\%))$} \\
\hline Yes & $445(9.2)^{1}$ & $473(22.3)^{2}$ & $191(0.6)$ \\
\hline
\end{tabular}

Source: European Social Survey, $3^{\mathrm{e}}$ round, own calculations

1 : difference between immigrants and natives is significant $(\mathrm{p}>0.05)$

2: difference between ethnic minorities and natives is significant $(p>0.05)$ 
Table 3a: Risk factors for depression among immigrants and ethnic minorities in Europe: fixed effects (weighted data)

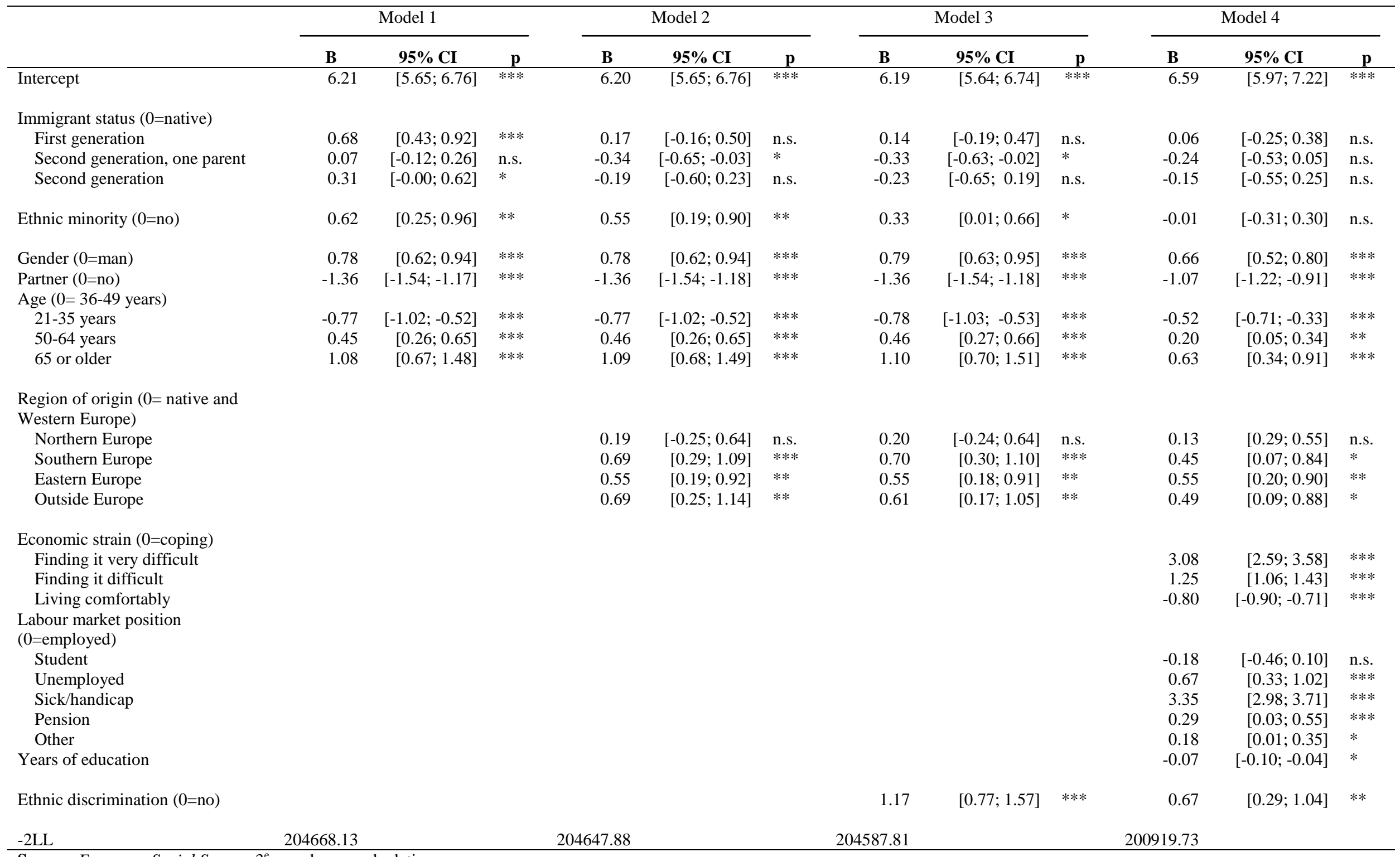


Table 3b: Risk factors for depression among immigrants and ethnic minorities in Europe: country level effects (random slopes) (weighted data)

\begin{tabular}{|c|c|c|c|c|c|c|c|c|c|c|c|c|}
\hline & \multicolumn{3}{|c|}{ Model 1} & \multicolumn{3}{|c|}{ Model 2} & \multicolumn{3}{|c|}{ Model 3} & \multicolumn{3}{|c|}{ Model 4} \\
\hline & P.E. & S.E. & $\mathbf{p}$ & P.E. & S.E. & p & P.E. & S.E. & $\mathbf{p}$ & P.E. & S.E. & $\mathbf{p}$ \\
\hline \multicolumn{13}{|l|}{ Parameter variance } \\
\hline \multirow{4}{*}{$\begin{array}{l}\text { Between } \\
\text { countries } \\
\text { Within countries }\end{array}$} & & & $* * *$ & & & $* *$ & & & $* * *$ & & & $* *$ \\
\hline & 1.60 & 0.50 & & 1.58 & 0.50 & & 1.56 & 0.49 & & 1.88 & 0.63 & \\
\hline & & & $* * *$ & & & $* *$ & & & $* * *$ & & & $* * *$ \\
\hline & 14.67 & 0.11 & & 14.66 & 0.11 & & 14.64 & 0.11 & & 13.20 & 0.10 & \\
\hline \multicolumn{13}{|l|}{ Variance components } \\
\hline Ethnic minority & 0.37 & 0.19 & $*$ & 0.36 & 0.19 & $*$ & 0.26 & 0.15 & & 0.21 & 0.14 & \\
\hline First generation & 0.11 & 0.09 & & 0.02 & 0.08 & & 0.01 & 0.08 & & 0.00 & 0.08 & \\
\hline Gender & 0.10 & 0.04 & $*$ & 0.10 & 0.04 & $*$ & 0.10 & 0.04 & $*$ & 0.07 & 0.03 & $*$ \\
\hline Partner & 0.13 & 0.05 & $* *$ & 0.13 & 0.05 & $*$ & 0.13 & 0.05 & $*$ & 0.08 & 0.04 & $*$ \\
\hline $21-35$ years & 0.26 & 0.10 & $* *$ & 0.25 & 0.10 & $* *$ & 0.25 & 0.10 & $* *$ & 0.12 & 0.06 & $*$ \\
\hline $50-64$ years & 0.13 & 0.06 & $*$ & 0.13 & 0.06 & $*$ & 0.13 & 0.06 & $*$ & 0.04 & 0.03 & \\
\hline 65 years or older & 0.80 & 0.26 & $* *$ & 0.79 & 0.26 & $* *$ & 0.79 & 0.26 & $* *$ & 0.28 & 0.12 & \\
\hline Outside Europe & & & & 0.28 & 0.18 & & 0.26 & 0.18 & & 0.15 & 0.14 & \\
\hline Ethnic discrimination & & & & & & & 0.24 & 0.20 & & 0.18 & 0.18 & \\
\hline Finding it very & & & & & & & & & & & & $* *$ \\
\hline difficult & & & & & & & & & & 1.01 & 0.39 & \\
\hline Finding it difficult & & & & & & & & & & 0.11 & 0.05 & $*$ \\
\hline Student & & & & & & & & & & 0.05 & 0.14 & \\
\hline Unemployed & & & & & & & & & & 0.37 & 0.19 & \\
\hline Sick/ handicapped & & & & & & & & & & 0.28 & 0.22 & \\
\hline Pension & & & & & & & & & & 0.23 & 0.10 & $*$ \\
\hline Other & & & & & & & & & & 0.04 & 0.04 & \\
\hline Years of education & & & & & & & & & & 0.00 & 0.00 & $* *$ \\
\hline
\end{tabular}

Source: European Social Survey, $3^{\mathrm{e}}$ round, own calculations

$* \mathrm{p}<0,05, * * \mathrm{p}<0,01, * * * \mathrm{p}<0,001$, Wald Z-test 
